\title{
Bioaccumulation, Subacute Toxicity, and Tissue Distribution of Engineered Titanium Dioxide Nanoparticles in Goldfish (Carassius auratus)
}

\author{
Mehmet Ates, ${ }^{1,2}$ Veysel Demir, ${ }^{1}$ Ragip Adiguzel, ${ }^{3}$ and Zikri Arslan ${ }^{2}$ \\ ${ }^{1}$ Department of Bioengineering, Tunceli University, Ataturk mahallesi Muhlis Akarsu caddesi, 62000 Tunceli, Turkey \\ ${ }^{2}$ Department of Chemistry and Biochemistry, Jackson State University, P.O. Box 17910, Jackson, MS 39217, USA \\ ${ }^{3}$ Department of Chemical Engineering, Tunceli University, Ataturk mahallesi Muhlis Akarsu caddesi, 62000 Tunceli, Turkey
}

Correspondence should be addressed to Mehmet Ates; mehmetates@tunceli.edu.tr

Received 27 June 2013; Revised 22 August 2013; Accepted 2 September 2013

Academic Editor: Xiaoming Li

Copyright (C) 2013 Mehmet Ates et al. This is an open access article distributed under the Creative Commons Attribution License, which permits unrestricted use, distribution, and reproduction in any medium, provided the original work is properly cited.

\begin{abstract}
The increased use of nanosized materials is likely to result in the release of these particles into the environment. It is, however, unclear if these materials are harmful to aquatic animals. In this study, the sublethal effects of exposure of low and high concentrations of titanium dioxide nanoparticles $\left(\mathrm{TiO}_{2} \mathrm{NPs}\right.$ ) on goldfish (Carassius auratus) were investigated. Accumulation of TiO $\mathrm{NPs}_{2}$ increased from 42.71 to $110.68 \mathrm{ppb}$ in the intestine and from 4.10 to $9.86 \mathrm{ppb}$ in the gills of the goldfish with increasing exposure dose from 10 to $100 \mathrm{mg} / \mathrm{L} \mathrm{TiO}_{2}$ NPs. No significant accumulation in the muscle and brain of the fish was detected. Malondialdehyde as a biomarker of lipid oxidation was detected in the liver of the goldfish. Moreover, $\mathrm{TiO}_{2} \mathrm{NPs}$ exposure inhibited growth of the goldfish. Although there was an increase (8.1\%) in the body weights of the goldfish for the control group, in the low and high exposure groups $1.8 \%$ increase and $19.7 \%$ decrease were measured, respectively. The results of this study contribute to the current understanding of the potential ecotoxicological effects of nanoparticles and highlight the importance of characterization of NPs in understanding their behavior, uptake, and effects in aquatic systems and in fish.
\end{abstract}

\section{Introduction}

Nanomaterials are used in a wide range of domestic appliances and household products, in the manufacture of textiles and electronics, as well as medical products and in bioremediation technology. There are also concerns about the environmental risks of nanotechnology which need to be balanced against their undoubted benefits to human society $[1,2]$. Handy and Shaw [3] reviewed the risks to human health and identified a number of exposure routes including the discharge of nanoparticles (NPs) to water and agricultural land. The chemistry and physical characteristics of the NPs themselves are key elements in determining their fate and behavior in aquatic systems. The large surface area, crystalline structure, and reactivity of some NPs may facilitate transport of these toxic materials in the environment [4]. Certain conditions such as presence of humic and fulvic acids, $\mathrm{pH}$, and specific cation concentrations may favor the stabilization of NPs in the water column [5]. The aquatic species are also at risk of exposure to the NPs and there is currently little known about their uptake, potential toxic effects, and behavior in aquatic systems.

Titanium dioxide $\left(\mathrm{TiO}_{2}\right)$ NPs have been widely used in several industries. Nanoparticulate $\mathrm{TiO}_{2}$ has been utilized as an ultraviolet radiation absorber in transparent sunscreen formulations [6] and in specialist photocatalytic coatings for glass [7]. The environmental chemistry of $\mathrm{TiO}_{2} \mathrm{NPs}$ has been partly investigated. $\mathrm{TiO}_{2}$ NPs can be dispersed in freshwater by sonication [8], but the primary particles tend to form aggregates of a few $100 \mathrm{~nm}$ dimensions, and the aggregates gradually precipitate from the water column over a few hours. $\mathrm{TiO}_{2}$ has two major crystal structures (rutile and anastase), and the surface reactivity of the NP is closely defined by the crystal structure [9].

There is an emerging literature on the effects of NPs for fish and aquatic invertebrates. NPs have previously been 
shown to accumulate in cells such as macrophages and hepatocytes $[10,11]$. Moreover, they are taken up into aquatic organisms such as fish, mollusks, crustaceans, and artemia [12-16]. Fish are excellent sentinels of environmental health as they are sensitive to a wide range of xenobiotic chemicals. Their position in the aquatic food chain means assessment of the populations, and health of fish can give an indication of the health of other lower levels of the food chain. Understanding the effects of NPs on fish is therefore an important aspect when considering the effects of NPs on the aquatic environment as a whole. Potential routes of uptake for NPs in fish include absorption via the gill epithelia, via the intestine epithelia as a result of dietary exposure and drinking, or via the skin [17].

The purpose of this exposure study was to determine subacute toxicity, accumulation, and tissue distribution of engineered $\mathrm{TiO}_{2} \mathrm{NPs}$ in goldfish (Carassius auratus). Due to the importance of their size and aggregation behavior [18-20], the NPs were characterized by transmission electron microscopy (TEM), and the size distribution of NPs was measured by dynamic light scattering (DSL). Fish tissues were used as in vitro model to determine the possible uptake of $\mathrm{TiO}_{2} \mathrm{NPs}$ into gill, intestine, muscle, and brain. Total Ti accumulation in each tissue was determined by inductively coupled plasma mass spectrometry (ICP-MS). In addition, MDA was determined as a cause of systemic oxidative stress.

\section{Materials and Methods}

2.1. Test Organism and Experimental Condition. A group of healthy goldfish (Carassius auratus) was purchased from a local pet shop. The initial body weight and length of the fish were measured as $4.53 \pm 0.06 \mathrm{~g}$ and $5.5 \pm 0.7 \mathrm{~cm}$, respectively. All fish were maintained in $30 \mathrm{~L}$ glass aquarium supplied via a flow-through system with dechlorinated tap water, enriched with oxygen at a temperature of $23 \pm 2^{\circ} \mathrm{C}$ and $\mathrm{pH}$ of 6.8. Fish were fed daily with commercially available fish feed flakes (TetraFin Goldfish flakes, Germany) at the amount of $0.5 \%$ of mean body weight of the fish. The goldfish were anesthetized using 3-aminobenzoic acid ethylester (MS-222; Aqua Life, Syndel Laboratories Ltd., Vancouver, BC, Canada) at a lethal dose for dissection (excess of $200 \mathrm{mg} / \mathrm{L}$ ), and a lower dose was used for all handling procedures $(150 \mathrm{mg} / \mathrm{L})$.

2.2. Reagents and Chemicals. $\mathrm{TiO}_{2} \mathrm{NPs}\left(\mathrm{TiO}_{2} 10-30 \mathrm{~nm} \mathrm{NPs}\right.$, $99.5 \%$ pure) were purchased, as uncoated nanomaterials, from Skyspring Nanomaterials Inc., in Houston, TX, USA. TEM image of NPs was spherical with an average particle size $\left(D_{50}\right)$ of $10-30 \mathrm{~nm}$ and approximate surface area of $50 \mathrm{~m}^{2} / \mathrm{g}$. The morphology of the NPs was rutile with pale yellow color, which is the most widely found polymorph of $\mathrm{TiO}_{2}$ in nature and in high pressure metamorphic rocks. The $\mathrm{TiO}_{2} \mathrm{NPs}$ were stored at room temperature in the laboratory until the implementation of the experimental studies.

Deionized water produced by Barnstead E-pure system with the resistivity of $18.0 \mathrm{M} \Omega \mathrm{cm}$ was used to prepare the exposure medium and experimental solutions. Trace metal grade nitric acid $\left(\mathrm{HNO}_{3}\right.$, Fisher Scientific) and hydrofluoric acid (HF, 99.99\%, Sigma Aldrich) used for dissolution of the goldfish were collected after the exposure to determine the total uptake levels. Stock titanium standard solution $\left(1000 \mu \mathrm{g} \mathrm{mL}^{-1}\right)$ was purchased from SCP Science (Champlain, NY). Calibration standards for ICP-MS analysis were prepared within a range from 0 to $500 \mu \mathrm{g} \mathrm{L}^{-1}$ from the stock Ti solution in $5 \% \mathrm{HNO}_{3}$. Carbon coated $\mathrm{Cu}$ TEM grids (300 mesh) were purchased from Electron Microscopy Sciences (EMS), Hatfield, PA.

2.3. Characterization of NPs. For preparation of exposure medium, $\mathrm{TiO}_{2} \mathrm{NPs}$ were weighed in polypropylene tubes and dispersed in deionized water. To achieve maximum dispersion, the suspension was homogenized using vortex (Daigger Vortex-Genie 2, Model G560) equipped with a titanium probe. Each suspension was exposed to mixture for about 2 minutes and then immediately transferred into the exposure glass tanks. The characterizations of the $\mathrm{TiO}_{2} \mathrm{NP}$ suspension were performed using TEM and DLS techniques. Size measurements in dried suspension were made by TEM, while DLS provided the size distribution for the hydrated forms of the NPs. In addition, Zeta potential measurements were conducted using the DLS instruments to elucidate the surface charges of the suspensions in the exposure medium.

For TEM measurements, a drop (ca. $8 \mu \mathrm{L}$ ) of solution was allowed to dry on a carbon-coated copper grid overnight $(\mathrm{CF} 300 \mathrm{Cu})$. The TEM grids were purchased from Electron Microscopy Sciences (EMS). Images were recorded by using JEOL-1011 TEM instrument with $0.2 \mathrm{~nm}$ lattice resolution and magnification power up to 106 under the accelerating voltage of 40 to $100 \mathrm{kV}$. Captured images were analyzed using Image J software. For DLS measurement, the protocol followed the standards of the Nanotechnology Characterization Laboratory [21]. A stock solution $(10 \mathrm{mg} / 100 \mathrm{~mL})$ was prepared with deionized water and diluted to a final concentration of $10 \mu \mathrm{g} / \mathrm{mL}$. Samples were then analyzed with Malvern Zetasizer Model Nano ZS according to manufacturer's protocols. Samples were read in disposable plastic Malvern Cells.

2.4. Experiment Design. NP exposure was conducted to assess acute toxicity and associated behavioral changes on goldfish by exposing the fish to two different doses, 10 and $100 \mathrm{mg} / \mathrm{L}$, of the $\mathrm{TiO}_{2} \mathrm{NPs}$, using 5 days static tests according to OECD 203 testing guidelines [22]. A control group was also set up without the test compound. Studies were carried out in an aquarium ( $30 \mathrm{~L}$ inner volume). The volume for $10 \mathrm{~L}$ level was marked and filled with freshwater followed by addition of the NP suspensions prepared as described above. Sight aeration was provided by a line extending to the bottom of the aquarium. Details of the experimental conditions are summarized in Table 1. Each scheme (control or treatments) was conducted in duplicate with 5 healthy goldfish. Individual length and weight of the fish were measured at the beginning and end of the experiment. The data obtained enabled calculation of the live weight and lengthwise increases and survival rates upon completion of the experiment.

2.5. Instrumental Analysis. At the end of the exposure, fish tissues were sampled for instrumental analysis, about $150 \mathrm{mg}$ of wet tissue was weighed and digested in Teflon vessels 
TABLE 1: Expanded design summary of goldfish (Carassius auratus).

\begin{tabular}{lccc}
\hline Parameter & Control & Group A & Group B \\
\hline $\begin{array}{l}\text { Volume of water in } \\
\text { aquarium (L) }\end{array}$ & 10 & 10 & 10 \\
$\begin{array}{l}\mathrm{TiO}_{2} \mathrm{NPs} \text { concentrations } \\
(\mathrm{mg} / \mathrm{L})\end{array}$ & 0 & 10 & 100 \\
$\begin{array}{l}\text { Duration of exposure } \\
\text { (day) }\end{array}$ & 5 & 5 & 5 \\
$\begin{array}{l}\text { Water temperature }\left({ }^{\circ} \mathrm{C}\right) \\
\begin{array}{l}\text { Oxygen (ppm) } \\
\text { pH value of water } \\
\text { (Start-End) }\end{array}\end{array}$ & $23 \pm 2$ & $23 \pm 2$ & $23 \pm 2$ \\
$\begin{array}{l}\text { Number of fish within } \\
\text { the aquarium }\end{array}$ & $6.30-6.05$ & $6.03-6.15$ & $6.63-6.45$ \\
\begin{tabular}{l} 
Number of replications \\
\hline
\end{tabular} & 2 & 5 & 5 \\
\hline
\end{tabular}

in $2 \mathrm{~mL}$ concentrated $\mathrm{HNO}_{3}$ and $0.5 \mathrm{~mL} \mathrm{HF}$ for 2 hours using a digestion block (DigiPrep MS, SCP Science) at $160^{\circ} \mathrm{C}$ according to protocols described elsewhere [23]. At the end, the contents were visually inspected for complete dissolution of $\mathrm{TiO}_{2}$ NPs (e.g., clear solution without any turbidity) and were diluted to $10 \mathrm{~mL}$ with deionized water. The sample solutions were analyzed by inductively coupled plasma mass spectrometry (ICP-MS) using a Varian 820MS ICP-MS instrument (Varian, Australia). ICP-MS is a powerful multielement technique for analysis of fish and other aquatic organisms for toxic metals even at subparts per billion levels because of its high sensitivity [24]. Titanium content of the solutions was measured to determine the accumulation pattern of the NPs across the dose of exposure. Total Ti concentration detected was then translated into corresponding $\mathrm{TiO}_{2} \mathrm{NP}$ concentration.

2.6. Oxidative Stress Parameter Analysis. The experiment was designed to allow sublethal physiological effects over the exposure period. The five days exposure time was chosen to enable some physiological or biochemical responses to the test organism. Five fish per treatment were collected from each tank at the end of the experiment for biochemical analysis. The extent of lipid peroxidation in the tissues was determined by measuring the quantity of malondialdehyde (MDA) [25]. Quantification of MDA was done following the methods described by Maness et al. [26], Esterbauer, and Cheeseman [27]. The method is based on the formation of pink MDA-thiobarbituric acid (TBA) adduct which has maximum absorption in acidic solution at $532 \mathrm{~nm}$. Briefly, the liver and muscle tissues were removed separately, immediately frozen in liquid nitrogen, and stored at $-20^{\circ} \mathrm{C}$ until needed. The frozen tissues were rinsed in 9-fold chilled $100 \mathrm{mmol} / \mathrm{L}, \mathrm{pH} 7.8$ sodium phosphate buffer solution, and homogenized by a hand-driven glass homogenizer. Approximately $150 \mathrm{mg}$ muscle tissue and $10 \mu \mathrm{L}$ BHT reagent were immediately transferred into $500 \mathrm{~mL}$ cold water in tube and then the sample was homogenized using sonicator (Sonic Dismembrator Model 100, Fisher Scientific). The samples were sonicated on ice by ultrasounds for $2 \mathrm{~min}$ at $80 \%$ power.
All samples and standards were incubated at $90^{\circ} \mathrm{C}$ for one hour, then centrifuged at $12000 \mathrm{rpm}$ for 15 minutes to separate the suspending tissue. The absorbance of the supernatant (reaction mixture) was measured at $532 \mathrm{~nm}$ with HP 8452A model diode array spectrophotometer. The concentration of the MDA formed was calculated based on a standard curve for the MDA (Sigma Chemical Co.) complex with TBA. The extent of lipid peroxidation was expressed in nanomoles (or micromoles) of MDA.

2.7. Statistical Analysis. All experiments were repeated twice independently, and data were recorded as the mean with standard deviation (SD). One-way analysis of variance (ANOVA) with Tukey's multiple comparisons was used to detect significant differences among groups. Student's $t$-test was used for paired comparisons of two groups. In all data analyses, a $P$ value $<0.05$ was considered statistically significant.

\section{Results and Discussion}

3.1. Characterization of NPs by TEM. $\mathrm{TiO}_{2}$ NPs are highly hydrophobic; therefore they aggregate substantially in aqueous solutions [28-30]. The stability and aggregation behaviors of NPs within aquatic media are determined by both the physicochemical properties of the liquid and the charge on the surface of the NPs. The degree of aggregation of NPs has been shown in some cases to affect toxicity in vitro, and aggregation of the NPs when suspended in water is a known issue for $\mathrm{TiO}_{2}$ NPs $[28,31]$. In this study, the water visibility decreased substantially with increasing concentration of $\mathrm{TiO}_{2}$ NPs, and at $100 \mathrm{~g} / \mathrm{L}$ level, the solution was cloudy. Similar aggregation phenomenon has been reported in many NP studies including $\mathrm{TiO}_{2}$ where aggregates of NPs can sink out of the solution very quickly [32]. The TEM images collected from the dried suspensions of stock solution and exposure medium are illustrated in Figure 1. The $\mathrm{TiO}_{2} \mathrm{NPs}$ aggregated significantly in water yielding large aggregates ranging from around 100 to as high as $1.0 \mu \mathrm{m}$ in size. Although aeration assisted in maintaining the homogeneity of the suspensions, aggregation could not be avoided at any concentration of $\mathrm{TiO}_{2} \mathrm{NPs}$.

3.2. Size Distribution and Surface Charge Measurement of NPs. Metal oxide particles tend to aggregate to various extents in water. The size distribution of the NPs is of interest in this study, since $\mathrm{TiO}_{2}$ NPs are highly hydrophobic; the particles size distribution in water was measured to determine the effect of the stability. The mean size distribution of $\mathrm{TiO}_{2}$ $\mathrm{NP}$ in water was calculated as $432 \pm 32 \mathrm{~nm}$ for $10 \mu \mathrm{g} / \mathrm{mL}$ NP suspension. Zeta potentials for the $\mathrm{TiO}_{2} \mathrm{NPs}$ in aqueous suspensions were obtained using the Henry Equation. A viscosity of $0.8872 \mathrm{cP}$, a dielectric constant of 78.5, and Henry function of 1.330 were used for the calculations. The mean zeta potential was calculated as $-31.6 \pm 4.5 \mathrm{mV}$ at a $\mathrm{pH}$ of 7.23 in $10 \mu \mathrm{g} / \mathrm{mL}$ aqueous suspensions of NP.

3.3. Accumulation in Organs of Goldfish. Uptake of nanomaterials by fish and other aquatic species has also been reported previously $[13,33]$. This study determined the accumulation 


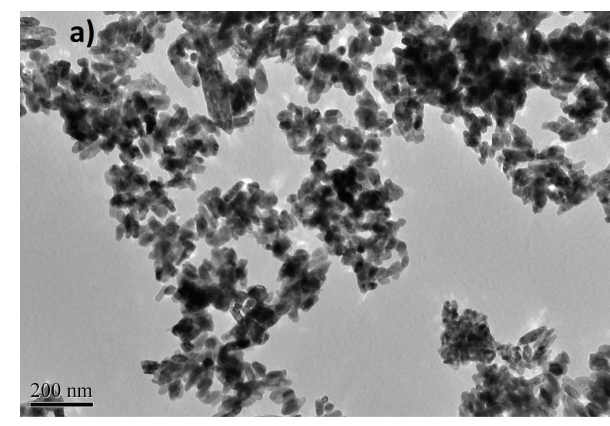

(a)

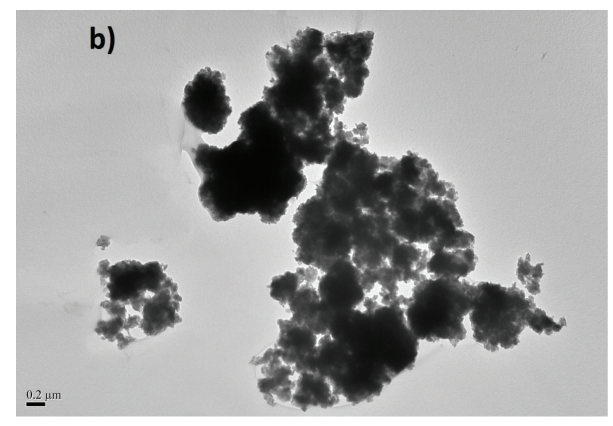

(b)

FIgURE 1: TEM images for $\mathrm{TiO}_{2}$ NPs from stock solution (a) and the exposure medium (b).

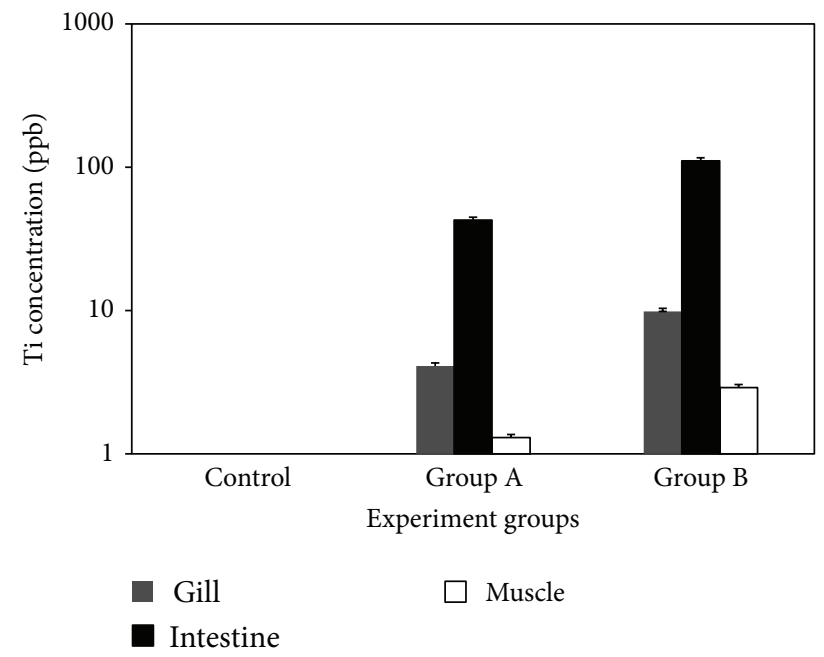

FIgURE 2: Titanium (Ti) levels in gill, intestine, and muscle of the goldfish at the end of the exposure experiments (Group A and Group B exposed to 10 and $100 \mathrm{mg} / \mathrm{L} \mathrm{TiO}_{2} \mathrm{NPs}$, resp.).

of the unmodified $\mathrm{TiO}_{2}$ NPs in fish tissues following exposure via the water column without the use of a solvent vehicle or prior modification of the NP surface. The chemical fate of the metal oxide NPs in the aquatic environment was determined through a comprehensive evaluation of uptake in fish with full characterization of the NPs in low and high exposure conditions. The gill, intestine, muscle, and brain of the goldfish were used as in vitro model to determine the possible uptake of $\mathrm{TiO}_{2}$ NPs into tissues. For $10 \mathrm{mg} / \mathrm{L}$ and for $100 \mathrm{mg} / \mathrm{L} \mathrm{TiO}_{2}$ exposure mediums, uptakes of $\mathrm{TiO}_{2} \mathrm{NPs}$ in intestine were measured as 42.71 and $110.68 \mathrm{ppb}$ and in gills as 4.10 and $9.86 \mathrm{ppb}$, respectively. ICP-MS analysis showed very small amount of $\mathrm{Ti}$ accumulation in the muscle and no accumulation in brain tissues of the goldfish (Figure 2). A study by Moger et al. [34], however, used coherent anti-Stokes Raman Scattering (CARS) to examine the gills of rainbow trout exposed to $5000 \mu \mathrm{g} \mathrm{L}^{-1} \mathrm{TiO}_{2} \mathrm{NPs}$ and confirmed the presence of small numbers of particle aggregates within the gill tissue.

3.4. Oxidative Stress. Lipid peroxidation generates a group of products among which are reactive electrophiles such as epoxides and aldehydes [27, 35, 36]. Malondialdehyde (MDA) is a major product of lipid peroxidation in aqueous solution. In this study, to elucidate the possible role of oxidative stress in the effects observed by $\mathrm{TiO}_{2} \mathrm{NPs}$ exposure, MDA content was assayed in liver and muscle of each experimental group. The analysis for MDA content of goldfish liver showed lipid peroxidation in the controls and exposure groups. The mean MDA levels in the liver of the fish were $4.1 \pm 0.5,7.6 \pm 1.1$, and $11.3 \pm 0.9 \mathrm{nmol} / \mathrm{gr}$ for control, and low and high dose exposure groups, respectively. No MDA level was measured in the muscles of the control and the exposure groups. Xiong et al. [29] also studied $\mathrm{TiO}_{2} \mathrm{NPs}_{\text {but }}$ on zebrafish and reported similar results as this study that oxidative effects were more severe in the livers of zebrafish exposed to $50 \mathrm{mg} / \mathrm{L} \mathrm{TiO}_{2} \mathrm{NPs}$.

Aqueous exposure to low and high dose of $\mathrm{TiO}_{2} \mathrm{NP}$ suspension did not cause any fish mortality during the experimental period ( $96 \mathrm{hr}$ ). Our data is in agreement with the literature, indicating low acute toxicity of $\mathrm{TiO}_{2} \mathrm{NPs}$ to fish survival. Similarly, Warheit et al. [37] reported that the Daphnia magna $48 \mathrm{hr}$ EC50 values and rainbow trout (Oncorhynchus mykiss) $96 \mathrm{hr}$ LC50 values for fine $\mathrm{TiO}_{2}$ particles and ultrafine $\mathrm{TiO}_{2}$ particles based on nominal concentrations were $>100 \mathrm{mg} / \mathrm{L}$, and the $\mathrm{LC}_{50}$ for $\mathrm{TiO}_{2} \mathrm{NPs}$ was also found to be over $500 \mathrm{mg} \mathrm{L}^{-1}$ in fathead minnow Pimephales promelas [38]. Furthermore, Zhu et al. [30] showed that exposure to $\mathrm{TiO}_{2}$ NPs at the concentrations up to $500 \mathrm{mg} / \mathrm{L}$ for $96 \mathrm{hr}$ did not affect hatching rate and did not cause deformity in embryonic zebrafish.

3.5. Effect of NPs on Growth Performance. Out of growth performance parameters for trial groups of goldfish, the best weight-wise growth as of the completion of the trial period was attained in the control group, where NPs were not exposed. The growth of the fish was inhibited with increasing exposure dose of $\mathrm{TiO}_{2}$ NPs. While the controls showed about $8.1 \%$ increase in body weight, those exposed to $10 \mathrm{mg} / \mathrm{L} \mathrm{NPs}$ showed a small increase (1.8\%) in body weight, and those exposed to $100 \mathrm{mg} / \mathrm{L}$ showed about $19.7 \%$ decrease in body weight at the end of the experiments (Figure 3 ).

\section{Conclusions}

A short period of exposure of the waterborne levels of 10 and $100 \mathrm{mg} / \mathrm{L} \mathrm{TiO}_{2}$ NPs is not lethal to the goldfish. Abnormal 


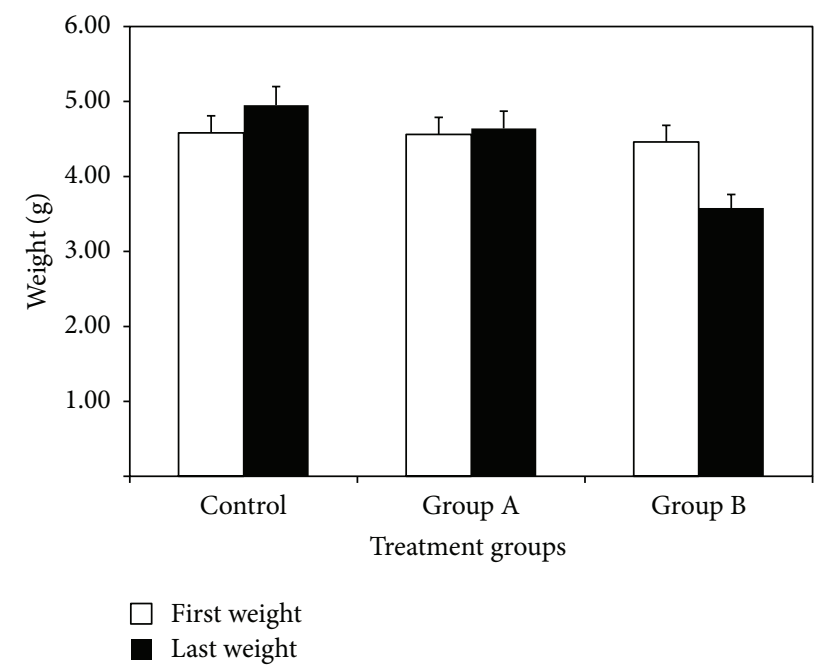

Figure 3: Average live weights (g) for the goldfish at the beginning and at the end of the experiments (Group A and Group B exposed to 10 and $100 \mathrm{mg} / \mathrm{L} \mathrm{TiO}_{2}$ NPs, resp.).

physiological and behavioral changes of the goldfish occurred under the higher concentrations during the experimental period. Since $\mathrm{TiO}_{2}$ NPs could cause oxidative stress and the decreases in the growth rate on fish, the release of $\mathrm{TiO}_{2}$ NPs into the aqueous environment may pose potential risks to aquatic organisms. This needs to be considered against the context of a general lack of knowledge of the fate, behavior, and bioavailability of these types of particles in natural systems and suggests a need for longer-term and more environmentally realistic NP exposure regimes to fully determine the transport capabilities of NPs in the aquatic environment. Although data on the behavior and effects of NPs in the environmental food chain would be of primary importance for understanding their overall potential hazard for ecosystems [39], very few studies in fish have examined the uptake and partitioning of $\mathrm{TiO}_{2}$ NPs, probably due to the difficulties involved in measuring low levels of $\mathrm{TiO}_{2}$ and limitations in analytical equipment.

\section{Conflict of Interests}

The authors declare that they have no conflict of interests.

\section{Acknowledgments}

This project is funded in part by grants from the National Institutes of Health (NIH) through Research Centers in Minority Institutions (RCMI) Program (Grant no. G12RR013459) and the US Department of Defense (DOD) through the Engineer, Research and Development Center (Vicksburg, MS), (Contract no. W912HZ-10-2-0045). The views expressed herein are those of the authors and do not necessarily represent the official views of the funding agencies and any of their subagencies. The authors thank Jackson State University, Biostatistical Support Unit, for assistance in statistical analysis.

\section{References}

[1] M. Crane and R. D. Handy, "An assessment of regulatory testing strategies and methods for characterizing the ecotoxicological hazards of nanomaterials," Report for Defra, Department for Environment, Food and Rural Affairs, London, UK, 2007.

[2] R. Owen and R. Handy, "Formulating the problems for environmental risk assessment of nanomaterials," Environmental Science and Technology, vol. 41, no. 16, pp. 5582-5588, 2007.

[3] R. D. Handy and B. J. Shaw, "Toxic effects of nanoparticles and nanomaterials: implications for public health, risk assessment and the public perception of nanotechnology," Health, Risk and Society, vol. 9, no. 2, pp. 125-144, 2007.

[4] T. Masciangioli and W. X. Zhang, "Environmental technologies at the nanoscale," Environmental Science and Technology, vol. 37, no. 5, pp. 102-108, 2003.

[5] M. Baalousha, A. Manciulea, S. Cumberland, K. Kendall, and J. R. Lead, "Aggregation and surface properties of iron oxide nanoparticles: influence of $\mathrm{pH}$ and natural organic matter," Environmental Toxicology and Chemistry, vol. 27, no. 9, pp. 18751882,2008

[6] G. J. Nohynek, J. Lademann, C. Ribaud, and M. S. Roberts, "Grey Goo on the skin? Nanotechnology, cosmetic and sunscreen safety," Critical Reviews in Toxicology, vol. 37, no. 3, pp. 251-277, 2007.

[7] J. Medina-Valtierra, C. Frausto-Reyes, J. Ramirez-Ortiz, and G. Camarillo-Martínez, "Self-cleaning test of doped $\mathrm{TiO}_{2}$-coated glass plates under solar exposure," Industrial and Engineering Chemistry Research, vol. 48, no. 2, pp. 598-606, 2009.

[8] G. Federici, B. J. Shaw, and R. D. Handy, "Toxicity of titanium dioxide nanoparticles to rainbow trout (Oncorhynchus mykiss): gill injury, oxidative stress, and other physiological effects," Aquatic Toxicology, vol. 84, no. 4, pp. 415-430, 2007.

[9] T. Watanabe, A. Nakajima, R. Wang et al., "Photocatalytic activity and photoinduced hydrophilicity of titanium dioxide coated glass," Thin Solid Films, vol. 351, no. 1-2, pp. 260-263, 1999.

[10] E. Witasp, N. Kupferschmidt, L. Bengtsson et al., "Efficient internalization of mesoporous silica particles of different sizes by primary human macrophages without impairment of macrophage clearance of apoptotic or antibody-opsonized target cells," Toxicology and Applied Pharmacology, vol. 239, no. 3, pp. 306-319, 2009.

[11] H. J. Johnston, M. Semmler-Behnke, D. M. Brown, W. Kreyling, L. Tran, and V. Stone, "Evaluating the uptake and intracellular fate of polystyrene nanoparticles by primary and hepatocyte cell lines in vitro," Toxicology and Applied Pharmacology, vol. 242, no. 1, pp. 66-78, 2010.

[12] J. E. Ward and D. J. Kach, "Marine aggregates facilitate ingestion of nanoparticles by suspension-feeding bivalves," Marine Environmental Research, vol. 68, no. 3, pp. 137-142, 2009.

[13] S. Kashiwada, "Distribution of nanoparticles in the see-through medaka (Oryzias latipes)," Environmental Health Perspectives, vol. 114, no. 11, pp. 1697-1702, 2006.

[14] X. Tao, J. D. Fortner, B. Zhang, Y. He, Y. Chen, and J. B. Hughes, "Effects of aqueous stable fullerene nanocrystals (nC60) on Daphnia magna: evaluation of sub-lethal reproductive responses and accumulation," Chemosphere, vol. 77, no. 11, pp. 1482-1487, 2009. 
[15] K. J. Lee, P. D. Nallathamby, L. M. Browning, C. J. Osgood, and $\mathrm{X}$. Nancy $\mathrm{Xu}$, "In vivo imaging of transport and biocompatibility of single silver nanoparticles in early development of zebrafish embryos," ACS Nano, vol. 1, no. 2, pp. 133-143, 2007.

[16] M. Ates, J. Daniels, Z. Arslan, and I. O. Farah, "Effects of aqueous suspensions of titanium dioxide nanoparticles on Artemia salina: assessment of nanoparticle aggregation, accumulation, and toxicity," Environmental Monitoring and Assessment, vol. 185, pp. 3339-3348, 2013.

[17] R. D. Handy, F. Von Der Kammer, J. R. Lead, M. Hassellöv, R. Owen, and M. Crane, "The ecotoxicology and chemistry of manufactured nanoparticles," Ecotoxicology, vol. 17, no. 4, pp. 287-314, 2008.

[18] L. K. Limbach, Y. Li, R. N. Grass et al., "Oxide nanoparticle uptake in human lung fibroblasts: effects of particle size, agglomeration, and diffusion at low concentrations," Environmental Science and Technology, vol. 39, no. 23, pp. 9370-9376, 2005.

[19] K. Fujiwara, H. Suematsu, E. Kiyomiya, M. Aoki, M. Sato, and N. Moritoki, "Size-dependent toxicity of silica nano-particles to Chlorella kessleri," Journal of Environmental Science and Health A, vol. 43, no. 10, pp. 1167-1173, 2008.

[20] C. Carlson, S. M. Hussein, A. M. Schrand et al., "Unique cellular interaction of silver nanoparticles: size-dependent generation of reactive oxygen species," Journal of Physical Chemistry B, vol. 112, no. 43, pp. 13608-13619, 2008.

[21] J. D. Clogston and A. K. Patri, "Zeta potential measurement," Methods in Molecular Biology, vol. 697, pp. 63-70, 2011.

[22] Organisation for Economic Co-operation and Development (OECD), Guideline for the Testing of Chemicals: (Part 203), OECD, Organisation for Economic Co-operation and Development, London, UK, 1992.

[23] Z. Arslan, M. Ates, W. McDuffy et al., "Probing metabolic stability of CdSe nanoparticles: alkaline extraction of free cadmium from liver and kidney samples of rats exposed to CdSe nanoparticles," Journal of Hazardous Materials, vol. 192, no. 1, pp. 192199, 2011.

[24] Z. Arslan, "Analysis of fish otoliths by electrothermal vaporization inductively coupled plasma mass spectrometry: aspects of precipitating otolith calcium with hydrofluoric acid for trace element determination," Talanta, vol. 65, no. 5, pp. 1326-1334, 2005.

[25] I. Erdelmeier, D. Gérard-Monnier, K. Régnard, N. Moze-Henry, J. Yadan, and J. Chaudière, "Reactions of 1-methyl-2-phenylindole with malondialdehyde and 4-hydroxyalkenals. Analytical applications to a colorimetric assay of lipid peroxidation," Chemical Research in Toxicology, vol. 11, no. 10, pp. 1176-1183, 1998.

[26] P. C. Maness, S. Smolinski, D. M. Blake, Z. Huang, E. J. Wolfrum, and W. A. Jacoby, "Bactericidal activity of photocatalytic $\mathrm{TiO}_{2}$ reaction: toward an understanding of its killing mechanism," Applied and Environmental Microbiology, vol. 65, no. 9, pp. 4094-4098, 1999.

[27] H. Esterbauer and K. H. Cheeseman, "Determination of aldehydic lipid peroxidation products: malonaldehyde and 4-hydroxynonenal," Methods in Enzymology, vol. 186, pp. 407-421, 1990.

[28] L. K. Adams, D. Y. Lyon, and P. J. J. Alvarez, "Comparative ecotoxicity of nanoscale $\mathrm{TiO}_{2}, \mathrm{SiO}_{2}$, and $\mathrm{ZnO}$ water suspensions," Water Research, vol. 40, no. 19, pp. 3527-3532, 2006.

[29] D. Xiong, T. Fang, L. Yu, X. Sima, and W. Zhu, "Effects of nanoscale $\mathrm{TiO}_{2}, \mathrm{ZnO}$ and their bulk counterparts on zebrafish: acute toxicity, oxidative stress and oxidative damage," Science of the Total Environment, vol. 409, no. 8, pp. 1444-1452, 2011.
[30] X. Zhu, L. Zhu, Z. Duan, R. Qi, Y. Li, and Y. Lang, “Comparative toxicity of several metal oxide nanoparticle aqueous suspensions to Zebrafish (Danio rerio) early developmental stage," Journal of Environmental Science and Health A, vol. 43, no. 3, pp. 278-284, 2008.

[31] X. Zhu, Y. Chang, and Y. Chen, "Toxicity and bioaccumulation of $\mathrm{TiO}_{2}$ nanoparticle aggregates in Daphnia magna," Chemosphere, vol. 78, no. 3, pp. 209-215, 2010.

[32] T. H. Chen, C. Y. Lin, and M. C. Tseng, "Behavioral effects of titanium dioxide nanoparticles on larval zebrafish (Danio rerio)," Marine Pollution Bulletin, vol. 63, no. 5-12, pp. 303-308, 2011.

[33] M. N. Moore, "Do nanoparticles present ecotoxicological risks for the health of the aquatic environment?" Environment International, vol. 32, no. 8, pp. 967-976, 2006.

[34] J. Moger, B. D. Johnston, and C. R. Tyler, "Imaging metal oxide nanoparticles in biological structures with CARS microscopy," Optics Express, vol. 16, no. 5, pp. 3408-3419, 2008.

[35] D. R. Janero, "Malondialdehyde and thiobarbituric acid-reactivity as diagnostic indices of lipid peroxidation and peroxidative tissue injury," Free Radical Biology and Medicine, vol. 9, no. 6, pp. 515-540, 1990.

[36] L. J. Marnett, "Oxy radicals, lipid peroxidation and DNA damage,” Toxicology, vol. 181-182, pp. 219-222, 2002.

[37] D. B. Warheit, R. A. Hoke, C. Finlay, E. M. Donner, K. L. Reed, and C. M. Sayes, "Development of a base set of toxicity tests using ultrafine $\mathrm{TiO}_{2}$ particles as a component of nanoparticle risk management," Toxicology Letters, vol. 171, no. 3, pp. 99-110, 2007.

[38] S. Hall, T. Bradley, J. T. Moore, T. Kuykindall, and L. Minella, "Acute and chronic toxicity of nano-scale $\mathrm{TiO}_{2}$ particles to freshwater fish, cladocerans, and green algae, and effects of organic and inorganic substrate on $\mathrm{TiO}_{2}$ toxicity," Nanotoxicology, vol. 3, no. 2, pp. 91-97, 2009.

[39] A. Kahru, H. C. Dubourguier, I. Blinova, A. Ivask, and K. Kasemets, "Biotests and biosensors for ecotoxicology of metal oxide nanoparticles: a minireview," Sensors, vol. 8, no. 8, pp. 51535170, 2008. 

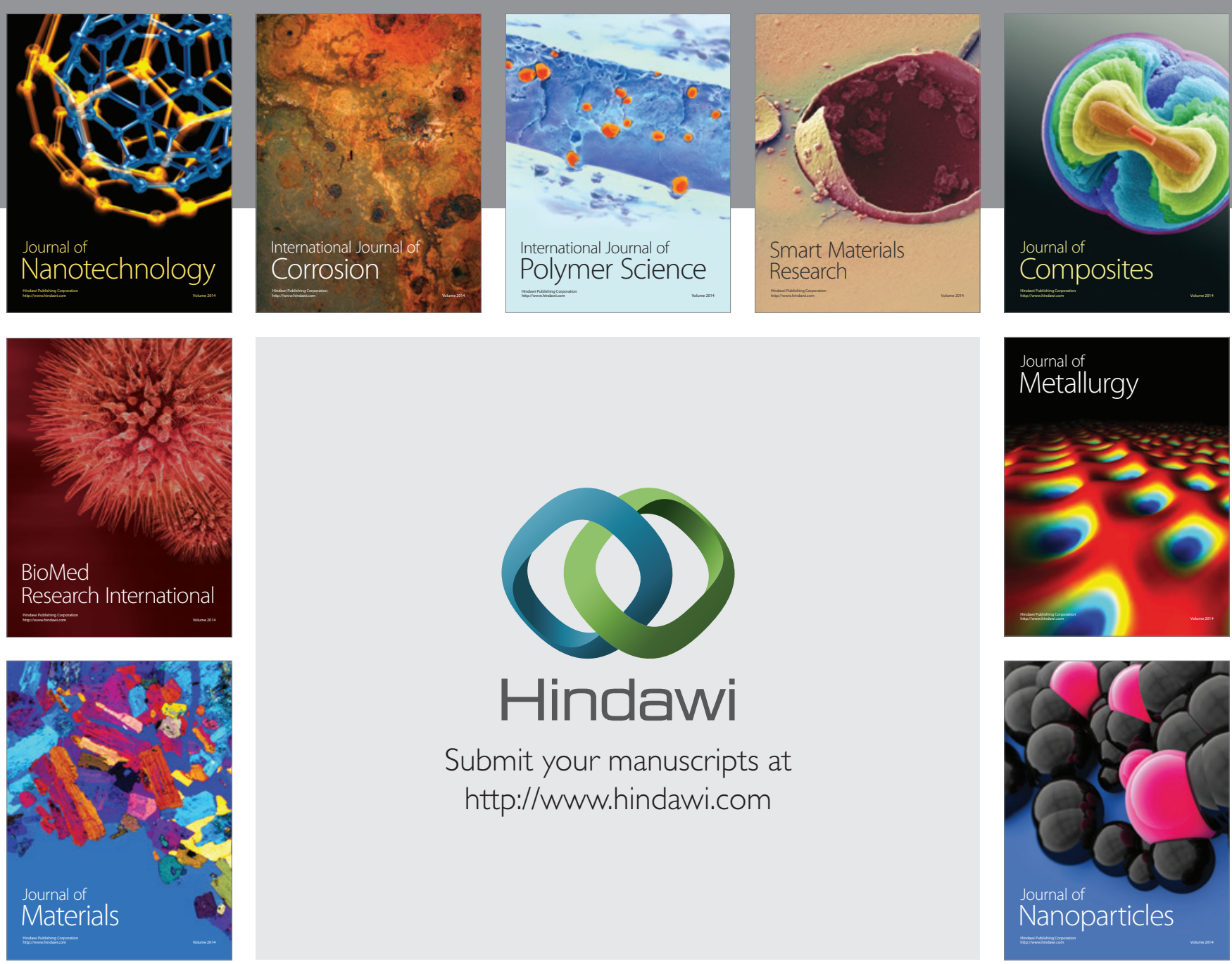

Submit your manuscripts at http://www.hindawi.com
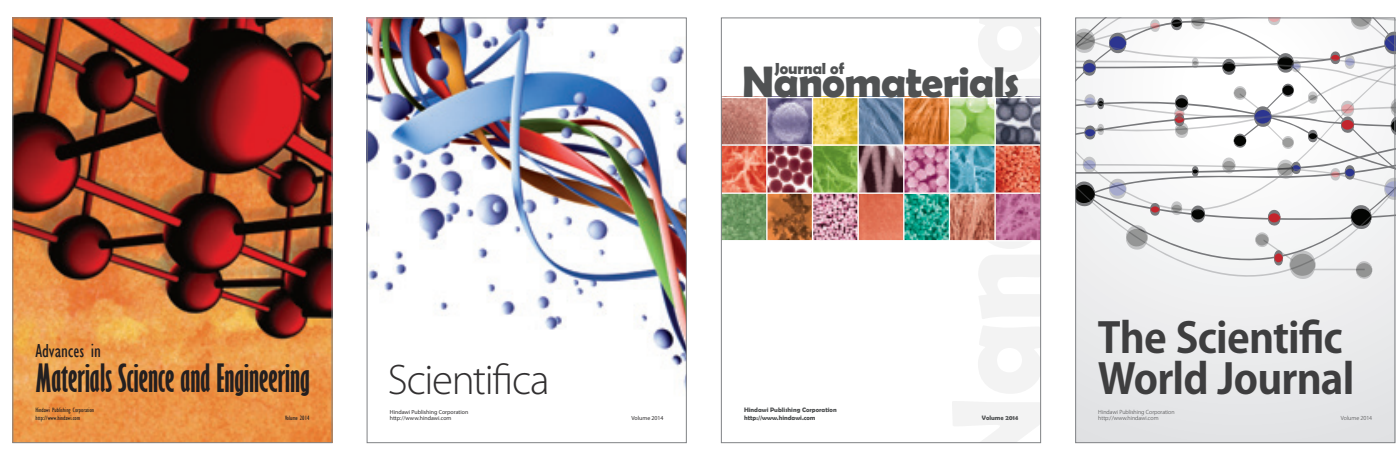

\section{The Scientific World Journal}
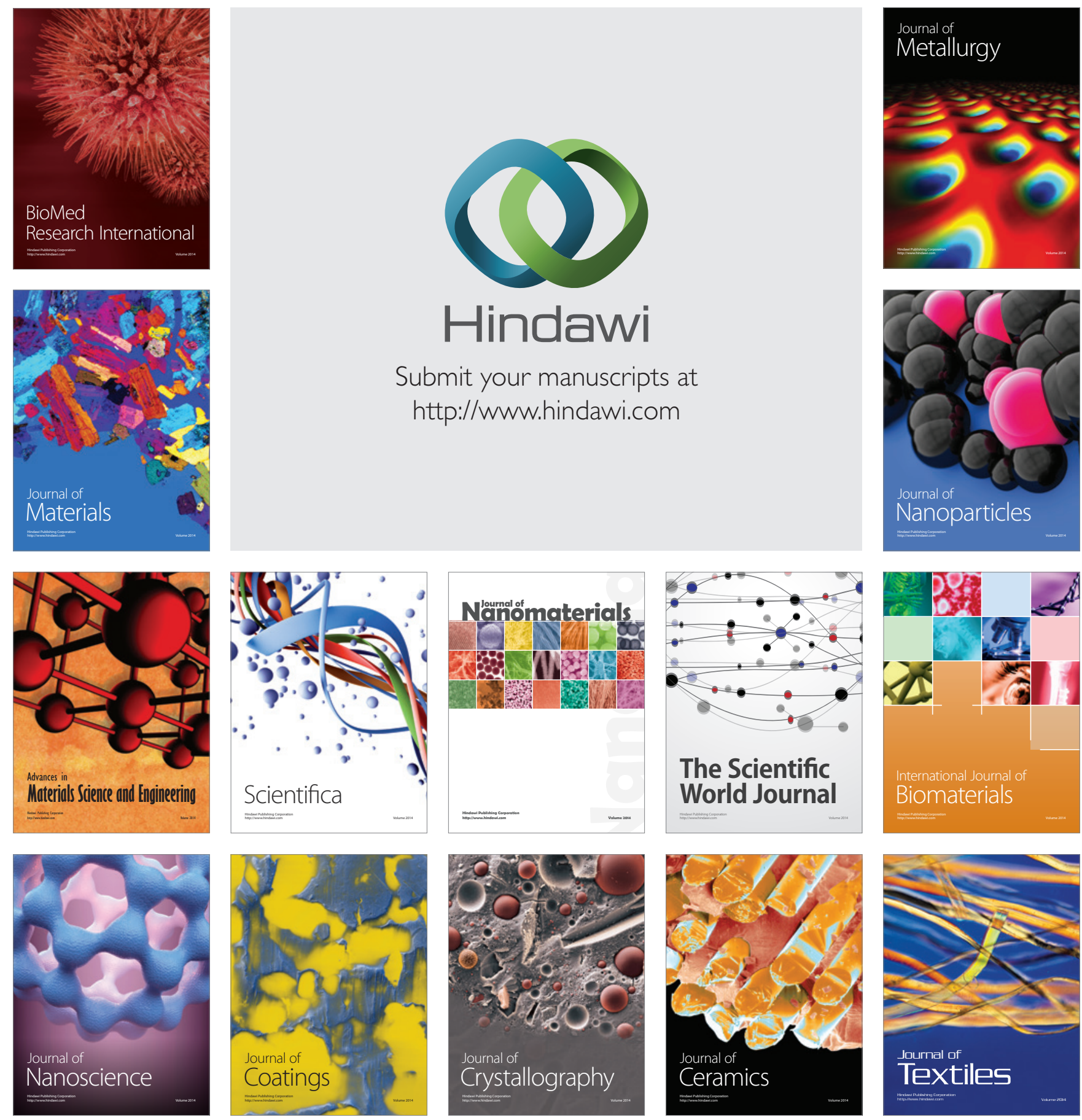